\title{
BMJ Open Physical and mental health of women exposed to intimate partner violence in the 10 years after having their first child: an Australian prospective cohort study of first-time mothers
}

\author{
Stephanie J Brown (10 , , ${ }^{1,2}$ Laura J Conway, ${ }^{1,3}$ Kelly M FitzPatrick, ${ }^{1,3}$ \\ Kelsey Hegarty, ${ }^{2}$ Fiona K Mensah, ${ }^{1}$ Sandra Papadopoullos, ${ }^{1}$ Hannah Woolhouse, ${ }^{1}$ \\ Rebecca Giallo, ${ }^{1,3}$ Deirdre Gartland (D) 1,3
}

To cite: Brown SJ, Conway LJ, FitzPatrick KM, et al. Physical and mental health of women exposed to intimate partner violence in the 10 years after having their first child: an Australian prospective cohort study of first-time mothers. BMJ Open 2020;10:e040891. doi:10.1136/ bmjopen-2020-040891

- Prepublication history and additional material for this paper are available online. To view these files, please visit the journal online (http://dx.doi org/10.1136/bmjopen-2020040891).

Received 01 June 2020 Revised 20 0ctober 2020 Accepted 20 November 2020

Check for updates

(c) Author(s) (or their employer(s)) 2020. Re-use permitted under CC BY-NC. No commercial re-use. See rights and permissions. Published by BMJ.

${ }^{1}$ Intergenerational Health, Murdoch Children's Research Institute, Parkville, Victoria, Australia

${ }^{2}$ Department of General Practice, University of Melbourne, Melbourne, Victoria, Australia ${ }^{3}$ Department of Paediatrics, University of Melbourne, Melbourne, Victoria, Australia

Correspondence to

Prof Stephanie J Brown;

stephanie.brown@mcri.edu.au

\section{ABSTRACT}

Objective To investigate mental and physical health of mothers exposed to recent and early postpartum intimate partner violence (IPV) in the 10 years after having their first child.

Design Prospective pregnancy cohort study.

Setting Women were recruited at six metropolitan public maternity hospitals in Melbourne, Australia and followed up at 1,4 and 10 years post partum.

Study measures Exposure to physical and/or emotional IPV was measured using the Composite Abuse Scale at 1 , 4 and 10 years. At 10-year follow-up, mothers reported on physical and mental health, and functional health status.

Participants 1507 first-time mothers enrolled at mean of 15 weeks' gestation.

Results One in three women experienced IPV during the 10 years after having their first child. Women experiencing recent IPV (19.1\%) reported worse physical and mental health than women not reporting IPV. Compared with women not reporting IPV, women experiencing recent IPV had higher odds of poor functional health status (Adj $\mathrm{OR}=4.5,95 \% \mathrm{Cl} 3.2$ to 6.3 ), back pain (Adj $\mathrm{OR}=2.0,95 \% \mathrm{Cl}$ 1.4 to 2.9), incontinence ( $\mathrm{Adj} \mathrm{OR}=1.8,95 \% \mathrm{Cl} 1.2$ to 2.6 ), depressive symptoms (Adj OR=4.9, 95\% Cl 3.2 to 7.5 ), anxiety (Adj $\mathrm{OR}=5.1,95 \% \mathrm{Cl} 3.0$ to 8.6 ) and post-traumatic stress symptoms (Adj OR=7.2, 95\% Cl 4.6 to 11.1 ) at 10 years. Women with past IPV at 1 and/or 4 years $(15.7 \%$ of the cohort) also had higher odds of physical and mental health problems. There was evidence of a gradient in health outcomes by recency of exposure to IPV.

Conclusions Both recent and past exposure to IPV are associated with poor maternal physical and mental health 10 years after a first birth. Health services and advocacy organisations providing support to women need to be aware of the consistent relationship between IPV and a range of physical and mental health conditions, which may persist even after IPV appears to have ceased.

\section{INTRODUCTION}

Intimate partner violence (IPV) is a global public health and human rights issue. ${ }^{1}$ The
Strengths and limitations of this study

- Strengths of this study include: recruitment of a community sample of first-time mothers in early pregnancy, the longitudinal design and low attrition of study participants.

- Twelve-month period prevalence of intimate partner violence (IPV) was assessed at three timepoints using a well-validated multidimensional measure.

- We used standardised measures of physical and mental health, with appropriate cut-off scores for identifying clinically significant symptoms in community samples.

- Selective attrition of the cohort is likely to have biased prevalence estimates for IPV and mental and physical health outcomes downwards, but is unlikely to have affected exposure-outcome associations.

- We used a composite variable combining experiences of physical and psychological IPV to represent exposure to violence, which may mask differences in the experiences of women exposed to different types of IPV.

WHO defines IPV as "behaviour within an intimate relationship that causes physical, sexual or psychological harm, including acts of physical aggression, sexual coercion, psychological abuse and controlling behaviours' by a partner or ex-partner and notes the particular vulnerability of childbearing women. ${ }^{2}$ The WHO multicountry study on women's health and domestic violence found that between $15 \%$ and $71 \%$ of ever-partnered women experience physical and/or sexual violence by a current or former partner at some stage in their lives. ${ }^{1}$ Several systematic reviews show that women abused by an intimate partner are more likely to experience depression, anxiety, post-traumatic stress symptoms, self-harm 
and sleep disorders. ${ }^{3-8}$ IPV has also been shown to be associated with poor physical health, including poor functional health status, chronic pain, gynaecological problems, gastrointestinal problems and other chronic medical conditions. ${ }^{6-12}$ A seminal US case-control study showed that women abused by an intimate partner were more likely to experience a variety of physical health problems including: headaches, back pain, sexually transmitted infections, vaginal bleeding, vaginal infections, pelvic pain, urinary tract infections, abdominal pain and digestive problems. ${ }^{13}$ Other studies have found associations with chronic pain, ${ }^{14}{ }^{15}$ increased use of pain medication ${ }^{101617}$ and poor functional health status. ${ }^{18} 19$ These health issues and subsequent health services use result in a high burden of disease, especially for women of childbearing age when IPV is very common. ${ }^{20}$

While there is clear evidence of associations between exposure to IPV and poor physical and mental health, research on the implications of IPV for women's physical and mental health remains an important area of inquiry for several reasons. First, many studies examining associations between IPV and women's health are cross-sectional, and thus unable to elucidate the temporal relationship of violence exposure and health outcomes. ${ }^{21} 22$ Second, population-based longitudinal studies which include measures of IPV commonly report retrospective data on lifetime exposure $e^{111423}$ and/or data on recent exposure to IPV. ${ }^{24}$ Few populationbased studies report prospective data on IPV collected over more than two waves of follow-up. ${ }^{26-30}$ Within these studies, long-term follow-up including repeated measurement of IPV extending over periods greater than 5 years is rare. ${ }^{27}{ }^{30}$ Third, as noted by Bacchus $e t$ $a l$, there has been a tendency for studies to focus on mental health outcomes, and hence, less is known about physical health or comorbid physical and mental health symptoms in the context of IPV. ${ }^{3}$ Finally, synthesis is complicated by differing definitions of IPV and use of non-standardised measures, particularly in older studies. ${ }^{28} 3132$ To our knowledge, there are no prospective mother and child cohort studies that have examined women's experiences of IPV and associated patterns of maternal mental and physical health concurrently, with follow-up beyond 36 months post partum.

Drawing on prospectively collected exposure and outcome data from an Australian cohort of first-time mothers, the objectives of this study are: (1) to determine the prevalence of recent, past and any exposure to IPV from birth to 10 years post partum; (2) to compare patterns of physical and mental health 10 years after having a first child among mothers reporting exposure to IPV at any stage during the 10 years after the birth with mothers not reporting exposure to IPV during this time period; and (3) to examine patterns of maternal physical and mental health problems 10 years after a first birth by timing of exposure to IPV (recent exposure vs past exposure).

\section{METHODS}

\section{Study design}

The study methods have been described in detail elsewhere. ${ }^{32}$ Briefly, women booking to give birth at six metropolitan public hospitals in Melbourne, Australia between 2003 and 2005 were invited to take part in a longitudinal study of maternal health. To be eligible for the study, women needed to be: nulliparous; $\geq 18$ years; $<24$ weeks' gestation at enrolment, and sufficiently fluent in English to complete study questionnaires and interviews. In all hospitals, women were mailed an invitation package which included: a plain language information sheet, letter of invitation, a consent form, baseline questionnaire and a reply-paid envelope for returning the questionnaire and consent form. At two hospitals, study staff also provided information to women at booking clinics, and at another, study staff attended prenatal education classes to distribute information about the study. This meant some women received multiple invitations to take part. In the initial phase of the study, women were invited to take part in several waves of follow-up from pregnancy to 18 months post partum. Women who joined the study were subsequently invited to take part in extended follow-up after second and subsequent births and when their first child was 4 and 10 years of age.

\section{Intimate partner violence}

Exposure to IPV was assessed at 1 year, 4 years and 10 years post partum using the Composite Abuse Scale (CAS).$^{33}$ The CAS was specifically designed and validated as a measure of different patterns of IPV as distinct from couple conflict. ${ }^{33-36}$ The short 18 -item version of the CAS (used at 12 months post partum) and longer 30-item version (used at 4 and 10 years) include items asking about emotional abuse (eg, "blamed me for their violent behaviour', 'tried to keep me from seeing my family') and physical abuse (eg, 'pushed, grabbed or shoved me', 'beat me up') by a current or former partner. Women are asked to indicate how often these actions have happened in the previous 12 months: never, once, several times, once per month, once per week or daily (scored 0-5). Women were categorised as experiencing IPV if they scored $\geq 1$ for physical abuse items and/or $\geq 3$ for emotional abuse items. ${ }^{33}$

\section{Maternal physical health}

Functional health status at 10 years post partum was assessed using the Medical Outcomes Study 36-item Short Form Health Survey (SF-36) Physical Health Component Summary (PCS) score. ${ }^{37} 38$ The physical health component score was calculated and transformed as described in the manual, then age standardised in line with Australian female population data. ${ }^{39}$ This produced Australian population weighted component score ranging from 0 to 100 , with a standardised population mean of 50 and SD of 10. The SF-36 PCS is reported divided into three categories: excellent ( $>1 \mathrm{SD}$ above the mean), average (within $1 \mathrm{SD}$ above or below the mean) and poor (>1 SD below the mean). In addition, women were asked to rate 
their health as excellent, very good, good, poor or very poor. Responses were dichotomised as 'excellent/very good' versus 'good, poor or very poor'.

Urinary and faecal incontinence at 10 years post partum were measured using standardised instruments matching internationally accepted symptom definitions. ${ }^{41}$ Following standardised terminology endorsed by the International Continence Society at the time of designing the study, women were defined as having urinary incontinence if they reported stress, urge or mixed incontinence, and as having faecal incontinence if they experienced leakage of liquid or solid stool. ${ }^{43}$ Other physical health problems such as extreme tiredness, back pain and severe period pain were assessed using a symptom checklist devised by the study investigators to assess common maternal health problems. Women were asked to indicate whether they had experienced any of the health problems listed in the last 3 months, with response options of never, rarely, occasionally and often. For the purpose of analysis, responses were dichotomised to compare women responding 'occasionally' or 'often' to those who said that they 'never' or 'rarely' experienced each symptom. Women were also asked to indicate whether they were currently experiencing any of a list of common medical conditions, including: asthma, heart disease, high blood pressure and diabetes.

\section{Maternal mental health}

Mental health at 10 years post partum was assessed using the Center for Epidemiological Studies Depression Scale (CES-D), the Beck Anxiety Inventory (BAI) and the PostTraumatic Stress Disorder Checklist-Civilian version (PCL-C). The CES-D is a 20-item measure designed to assess depressive symptoms in the general population. ${ }^{44}$ We used the cut-off score of $\geq 20$ which has been found to have good sensitivity and specificity for identifying major depressive disorder in community samples. ${ }^{45}$ The BAI is a 21-item measure originally developed to differentiate anxiety symptoms from depression. ${ }^{46}$ We used the recommended cut-off score of $\geq 16$ for identifying clinically significant anxiety symptoms. ${ }^{46}{ }^{47}$ The PCL-C is a 17 -item scale that has been shown to have good reliability and diagnostic accuracy for identifying post-traumatic stress symptoms matching the Diagnostic and Statistical Manual of Mental Disorders, fourth edition criteria. ${ }^{48-50}$ The cutoff score of $\geq 35$ was selected as the optimal cut-point for use in community samples. ${ }^{51}$ In addition, use of psychotropic medication (antidepressants or anti-anxiety medication) was assessed by asking women to report on the use of medications in the previous month (yes/no). Finally, thoughts of self-harm were assessed based on responses to item 10 of the Edinburgh Postnatal Depression Scale. ${ }^{52} 53$

\section{Sociodemographic characteristics}

Social characteristics including maternal age, relationship status, country of birth and education were collected at study enrolment. Further information regarding study measures is available in previous papers. ${ }^{27} 32$
We were mindful of potential risks to women of participation in research asking about IPV and mental health, and took appropriate steps to ensure women's safety. These included: giving women the option to receive questionnaires at a private mail box or alternative address to ensure that mail would not be opened by anyone other than the participant; following up women to offer support and referral when it was apparent that women were isolated and/or lacking support to deal with IPV or mental health issues. In addition, we opted not to include direct questions about IPV in the baseline questionnaire completed in early pregnancy as we could not be confident that the initial invitation package containing the baseline questionnaire would not be read by women's partners.

\section{Patient and public involvement}

Study procedures, information materials, selfadministered questionnaires and interview schedules were piloted with a small group of women $(n>20)$ to assess acceptability and relevance, and to ensure that any problems relating to the clarity of instructions and explanations were sorted out prior to commencing each stage of follow-up. Feedback from pilot participants informed final selection of study measures. We maintain a study website and distribute study newsletters once or twice per year to all participants, including pilot study participants.

\section{ANALYSIS}

Data were analysed using Stata V.16. ${ }^{54}$ Participant characteristics at study enrolment were compared with routinely collected data for nulliparous women giving birth as public patients in the state of Victoria during the study period in order to assess the representativeness of the sample in relation to key demographic and obstetric characteristics. Twelve-month period prevalence of exposure to IPV was calculated for three time periods: the 1st, 4 th and 10th years. Data were then combined to provide measures of: exposure to IPV at any of these three time periods, recent exposure (experiences of IPV during the 12 months prior to 10-year follow-up, irrespective of whether IPV had been reported previously) and past exposure (defined as exposure to IPV during the first and/or fourth year post partum, but not during the 12 months prior to 10 -year follow-up).

Univariable and multivariable logistic regression was used to assess associations between exposure to IPV during the 10 years after giving birth to a first child and functional health status, prevalence of physical health problems, medical conditions and mental health problems at 10 years post partum. In addition, we conducted a second set of regression analyses to assess associations between recent and past exposure to IPV and the same health outcome measures at 10 years post partum. Data are presented as adjusted ORs and 95\% CIs adjusting for potential confounding by maternal age (for a priori reasons related to the impact of ageing on physical 
health) and education (as a marker of socioeconomic status during pregnancy).

Analyses were initially conducted as complete case analyses and then repeated using multiply imputed data to account for selective attrition over time. Forty data sets were imputed using chained equation modelling. The imputation model included variables associated with attrition, variables significantly associated with outcome variables at 10-year follow-up (eg, depressive symptoms, anxiety symptoms, post-traumatic stress symptoms), and variables included in multivariable models (ie, maternal age, education). Patterns of association between variables were similar in analyses with multiple imputation and complete case analyses, but different prevalence estimates were obtained. For example, the prevalence of recent and past IPV was $13.9 \%$ and $15.8 \%$, respectively, in complete case analyses and $19.1 \%$ and $15.7 \%$ in imputed data. The point prevalence of depressive symptoms at 10 years was $15.4 \%$ in complete case analyses and $18.5 \%$ in imputed data. As imputed data are more likely to give a robust picture of prevalence of IPV and mental and physical health symptoms at 10-year follow-up, results are presented using multiply imputed data $(n=1507)$.

\section{RESULTS}

\section{Study participants}

A total of 1507 women met eligibility criteria and were enrolled in the study in early pregnancy (mean gestation $=15.0$ weeks, $\mathrm{SD}=3.1$, range $6-24$ weeks). We estimate that around one in three women who received an information package enrolled in the study. Comparison of participant characteristics with routinely collected data for all nulliparous women $\geq 18$ years giving birth as public patients in the state of Victoria in the study period showed that the sample was representative in terms of method of birth, infant birth weight and gestation. Younger women (18-24 years, 14.1\% vs $29.8 \%$ ) and women born overseas of non-English speaking background $(16.2 \%$ vs $21.5 \%)$ were underrepresented. The mean age of study participants at the time of giving birth was 30.9 years $(\mathrm{SD}=4.8$ years, range $18-50$ years). In early pregnancy, the majority of women were living with their partner $(60.7 \%$ married, $34.6 \%$ cohabiting). Additional information regarding participant characteristics at study enrolment is available in previous publications. ${ }^{32} 55$

Participation in phase 1 (from pregnancy to 18 months post partum) was as follows: 1507 in early pregnancy (mean of 15 weeks' gestation); $1431(95.0 \%)$ at 3 months; $1400(92.9 \%)$ at 6 months; $1357(90.0 \%)$ at 12 months; and $1327(88.1 \%)$ at 18 months post partum (see figure 1). Eighty-nine percent of the original cohort $(n=1345)$ consented to take part in extended follow-up. Of these, 1102 women $(73.1 \%$ of the original cohort) took part in 4-year follow-up and $952(63.2 \%$ of the original cohort) completed 10-year follow-up.

\section{Pregnancy}

Early pregnancy

$(<24$ weeks)

1507 women in cohort

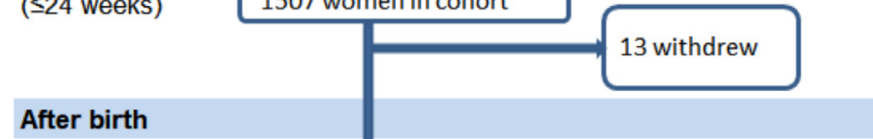

After birth

3 months

1494 participants

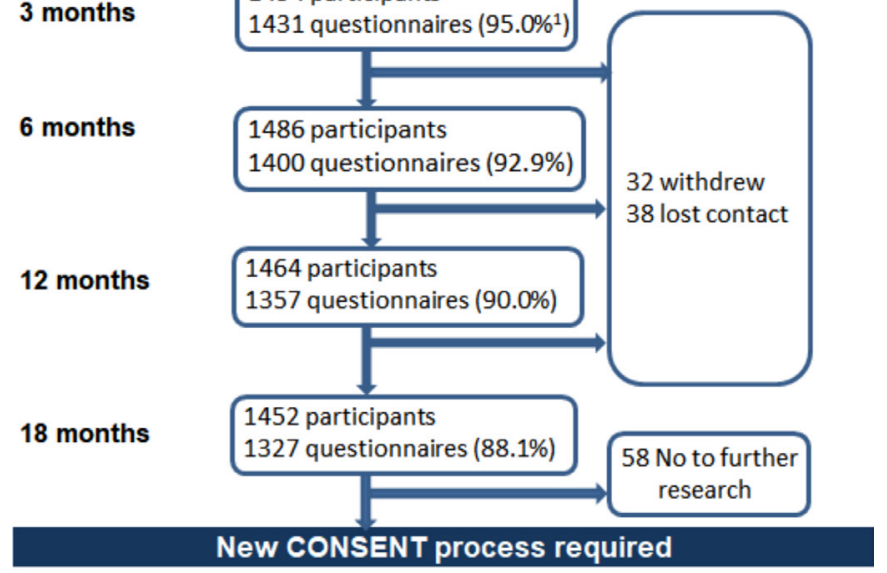

1366 participants invited

1345 in cohort (consented)

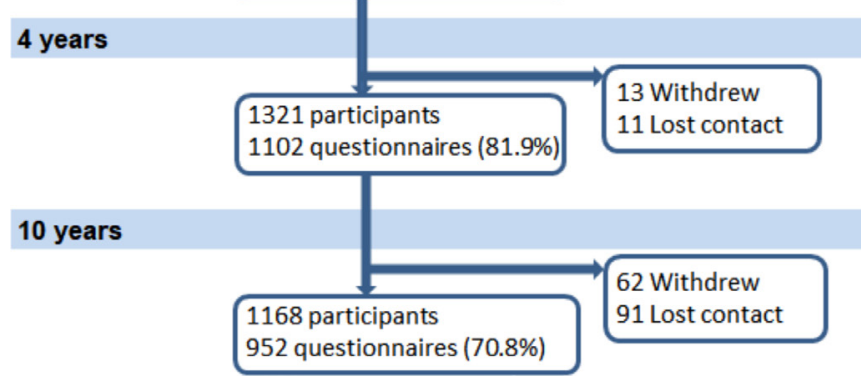

Figure 1 Flowchart of study participation. ${ }^{1} 15$ women delivered $<32$ weeks; all percents calculated using total cohort (phase $1 \mathrm{n}=1507$, phase $2 \mathrm{n}=1345$.

Selective attrition occurred across waves of the study. Younger women, those in receipt of a government benefit as their main source of income, women who did not have tertiary qualifications, women born overseas of non-English speaking background and women who reported IPV in the early years of the study were less likely to complete 10-year follow-up (see online supplemental table 1).

\section{Exposure to IPV}

One in three women in the cohort $(34.8 \%, 95 \%$ CI $31.8 \%$ to $37.7 \%$ ) reported IPV involving a current or former intimate partner between the birth of their first child and their child turning 10 years of age (see table 1). Just under one in five women $(19.0 \%)$ reported IPV in the first 12 months post partum, 20.5\% in the year prior to 4-year follow-up and $19.1 \%$ in the year prior to 10-year follow-up. Applying study definitions, $19.1 \%$ of women reported recent IPV and $15.7 \%$ past IPV. Almost two-thirds of women who reported 
Table 1 Prevalence of intimate partner violence (IPV) during the 10 years after a first birth $(n=1507)$

\begin{tabular}{l} 
Proportion of women \\
experiencing IPV \\
\hline$\%(95 \% \mathrm{Cl})$
\end{tabular}

$\%(95 \% \mathrm{Cl})$

\begin{tabular}{ll}
\hline $\begin{array}{l}\text { Any IPV reported (1, } 4 \text { and/or } 10 \\
\text { years) }\end{array}$ & 34.8 (31.8 to 37.7$)$ \\
\hline No IPV reported & $65.2(62.3$ to 68.2$)$ \\
\hline IPV in first year post partum & $19.0(16.9$ to 21.1$)$ \\
\hline IPV in fourth year post partum & $20.5(18.0$ to 23.0$)$ \\
\hline IPV in 10th year post partum & $19.1(16.1$ to 22.1$)$ \\
\hline Recent IPV* & $19.1(16.1$ to 22.1$)$ \\
\hline Past IPV $†$ & $15.7(13.3$ to 18.1$)$ \\
\hline
\end{tabular}

*Experiences of IPV during the 12 months prior to 10 -year followup, irrespective of whether IPV had been reported previously. †Experiences of IPV during the first and/or fourth year postpartum, but not during the 12 months prior to 10 -year follow-up.

recent exposure had also reported IPV in earlier waves of follow-up $(65.1 \%)$.

\section{Patterns of physical and mental health associated with any exposure to IPV}

To assess associations between exposure to IPV over the course of the first 10 years post partum and mothers' physical and mental health 10 years after their first birth, we conducted a series of multivariable logistic regression analyses reported in tables 2 and 3 (aim 2). Table 2 reports data on functional health status, prevalence of common maternal health problems and medical conditions for the cohort as a whole, and results of regression analyses assessing associations with exposure to IPV (with adjustment for maternal age and highest education qualification). Women who had experienced IPV (in the first 12 months, 4th and/or 10th year post partum) had poorer functional health status (score of $<40$ on SF-36 PCS) and were more likely to rate their health as less than very good, compared with women who had not reported IPV at any follow-up. They were also more likely to report extreme tiredness, back pain, severe headaches or migraines, severe period pain and urinary incontinence at 10 years post partum. Compared with women not reporting IPV, women with exposure to IPV also had raised odds of faecal incontinence, with the CI bordering on 1. More than half of women exposed to IPV during the first 10 years post partum reported experiencing three or more of these health problems in the last 3 months, compared with just over one-third of women not reporting IPV. Women exposed to IPV also had raised odds of reporting asthma and cardiovascular and metabolic conditions (high blood pressure, heart disease and/ or diabetes), with CIs bordering 1.

Table 3 reports data on prevalence of mental health symptoms and use of psychotropic medication for the cohort as a whole, and the associations between exposure to IPV (in the first 12 months, 4th or 10th year post partum) and women's mental health 10 years after a first birth. One in four women $(26.4 \%)$ in the cohort reported experiencing depressive, anxiety and/or posttraumatic stress symptoms at 10 years post partum. Almost one in five women in the cohort $(18.9 \%)$ had taken psychotropic medication in the past month, and $8.9 \%$ reported thoughts of self-harm in the week prior to 10-year follow-up. Women who had experienced IPV (in the first 12 months, 4th and/or 10th year post partum) had a three to four times higher likelihood of experiencing depressive symptoms (CES-D $\geq 20$ ), anxiety symptoms (BAI $\geq 16$ ), post-traumatic stress symptoms (PCL-C $\geq 35$ ) and reporting thoughts of self-harm, compared with women not reporting IPV. They were also more likely to be taking psychotropic medication at 10-year follow-up. Of the women reporting IPV at any follow-up, almost one in three reported depressive symptoms and/or posttraumatic stress symptoms at 10-year follow-up, one in four were taking psychotropic medication, just under one in four reported anxiety symptoms and one in eight had experienced thoughts of self-harm in the week prior to completing 10-year follow-up (table 3).

Patterns of physical and mental health associated with recent and past IPV exposure

To address aim 3, we stratified the sample into three groups: women who reported recent IPV, women who reported past IPV and women who never reported IPV. Figure 2 illustrates the functional health status, and prevalence of physical and mental health problems of women with recent and past exposure to IPV, compared with women who never reported IPV as the reference category. Results are also reported in table 4. Clear evidence of a gradient in health outcomes is apparent in the overall measure of functional health status provided by the SF-36 PCS and self-rated health measures. Around half $(55 \%)$ of women with recent IPV and $30 \%$ of women with past IPV had a below average score on the SF-36 PCS, compared with $21.1 \%$ of women who never reported IPV. The measure of self-rated health illustrated a similar pattern with $54.3 \%$ of women with recent IPV and $48.3 \%$ of women with past IPV rating their health as less than very good compared with $33.2 \%$ of women who never reported IPV. Odds of common physical health issues (eg, exhaustion, back pain, urinary incontinence) were between 1.6 and 3.0 times higher for women with recent exposure to IPV, and between 1.4 and 2.0 times higher for women with past exposure to IPV, compared with women who never reported IPV. On the whole, women with recent exposure to IPV had the highest odds of reporting physical and psychological morbidity, with patterns of morbidity for women reporting past exposure intermediate between those of women reporting recent exposure and women never reporting IPV. The two exceptions to this pattern were asthma and heart disease/diabetes, where women with past exposure had slightly higher odds of morbidity than women with recent exposure. 
Table 2 Physical health of mothers at 10 years post partum comparing women reporting/not reporting IPV at any follow-up $(n=1507)$

\begin{tabular}{llllll} 
Cohort & IPV at 1, 4 and/or 10 years \\
\hline$\%(95 \% \mathrm{Cl})$ & $\begin{array}{l}\text { No } \\
\%\end{array}$ & $\begin{array}{l}\text { Yes } \\
\%\end{array}$ & Adj OR & $95 \% \mathrm{Cl}$ & P value
\end{tabular}

\section{Functional health status}

SF-36 Physical Component Score†

\begin{tabular}{|c|c|c|c|c|c|c|}
\hline Average or better $(\geq 40)$ & 71.0 (68.0 to 74.0$)$ & 78.9 & 56.3 & 1.0 & ref & \\
\hline Poor health $(<40)$ & 29.0 (26.0 to 32.0$)$ & 21.1 & 43.7 & 2.8 & 2.1 to 3.8 & $<0.001$ \\
\hline \multicolumn{7}{|l|}{ Self-rating of health (SF-36) } \\
\hline Excellent/very good & 60.4 (57.2 to 63.6$)$ & 66.8 & 48.4 & 1.0 & ref & \\
\hline Good/fair/poor & 39.6 (36.4 to 42.8$)$ & 33.2 & 51.6 & 2.1 & 1.5 to 2.8 & $<0.001$ \\
\hline \multicolumn{7}{|l|}{ Common health issues } \\
\hline \multicolumn{7}{|c|}{ Extreme tiredness or exhaustion } \\
\hline Never/rarely & 35.6 (32.4 to 38.7 ) & 41.3 & 24.8 & 1.0 & ref & \\
\hline Occasionally/often & 64.4 (61.3 to 67.6$)$ & 58.7 & 75.2 & 2.2 & 1.5 to 3.1 & $<0.001$ \\
\hline \multicolumn{7}{|l|}{ Back pain } \\
\hline Never/rarely & 43.2 (39.8 to 46.6$)$ & 48.2 & 33.9 & 1.0 & ref & \\
\hline Occasionally/often & 56.8 (53.4 to 60.2$)$ & 51.8 & 66.1 & 1.8 & 1.4 to 2.4 & $<0.001$ \\
\hline \multicolumn{7}{|c|}{ Severe headaches or migraines } \\
\hline Never/rarely & 66.7 (63.3 to 70.1$)$ & 70.5 & 59.5 & 1.0 & ref & \\
\hline Occasionally/often & 33.3 (29.9 to 36.7$)$ & 29.5 & 40.5 & 1.6 & 1.2 to 2.1 & 0.002 \\
\hline \multicolumn{7}{|c|}{ Urinary incontinence ( $\geq$ monthly) } \\
\hline No & 65.9 (62.9 to 69.0$)$ & 69.3 & 59.6 & 1.0 & ref & \\
\hline Yes & 34.1 (31.0 to 37.1$)$ & 30.7 & 40.4 & 1.6 & 1.2 to 2.2 & 0.001 \\
\hline \multicolumn{7}{|l|}{ Faecal incontinence } \\
\hline No & 87.9 (85.6 to 90.3$)$ & 89.2 & 85.6 & 1.0 & ref & \\
\hline Yes & $12.1(9.7$ to 14.4$)$ & 10.8 & 14.4 & 1.3 & 0.8 to 2.1 & 0.243 \\
\hline \multicolumn{7}{|l|}{ Severe period pain } \\
\hline Never/rarely & 73.9 (70.6 to 77.2$)$ & 77.1 & 68.0 & 1.0 & ref & \\
\hline Occasionally/often & 26.1 (22.8 to 29.4$)$ & 22.9 & 32.0 & 1.6 & 1.1 to 2.2 & 0.012 \\
\hline \multicolumn{7}{|c|}{ Number health issues reported (0-6) } \\
\hline $0-2$ & 56.4 (53.3 to 59.6$)$ & 63.5 & 43.3 & 1.0 & ref & \\
\hline 3 or more & 43.6 (40.4 to 46.7 ) & 36.5 & 56.7 & 2.2 & 1.7 to 3.0 & $<0.001$ \\
\hline
\end{tabular}

\section{Chronic medical conditions (past year)}

\begin{tabular}{|c|c|c|c|c|c|c|}
\hline \multicolumn{7}{|c|}{ Asthma } \\
\hline No & 87.0 (84.5 to 89.5$)$ & 88.2 & 84.8 & 1.0 & ref & \\
\hline Yes & 13.0 (10.5 to 15.5$)$ & 11.8 & 15.2 & 1.3 & 0.8 to 2.0 & 0.276 \\
\hline \multicolumn{7}{|c|}{ High blood pressure, heart disease and/or diabetes } \\
\hline No & 92.8 (90.9 to 94.6$)$ & 94.0 & 90.6 & 1.0 & ref & \\
\hline Yes & $7.2(5.4$ to 9.1$)$ & 6.0 & 9.4 & 1.7 & 1.0 to 2.9 & 0.052 \\
\hline
\end{tabular}

${ }^{*}$ Adjusted for maternal age and highest education level.

†Age standardised scale (mean=50, $S D=10$ ). Poor health categorised as lower than $1 \mathrm{SD}$ below the mean that is, Physical Component Score of less than 40.

IPV, intimate partner violence; SF-36, 36-item Short Form Health Survey.

Similar, but even more marked effects, were apparent for mental health problems (see figure 2 and table 4 ). Odds of individual mental health symptoms (ie, depressive, anxiety and post-traumatic stress symptoms, thoughts of self-harm) were between 4.9 and 7.2 times higher for women with recent IPV, and between 1.6 and 
Table 3 Mental health of mothers at 10 years post partum comparing women reporting/not reporting IPV at any follow-up $(n=1507)$

\begin{tabular}{|c|c|c|c|c|c|c|}
\hline & \multirow{2}{*}{$\begin{array}{l}\text { Cohort } \\
\%(95 \% \mathrm{Cl})\end{array}$} & \multicolumn{5}{|c|}{ IPV at 1, 4 and/or 10 years } \\
\hline & & No & Yes & Adj OR* & $95 \% \mathrm{Cl}$ & $P$ value \\
\hline \multicolumn{7}{|c|}{ Depression (CES-D $\geq 20$ ) } \\
\hline Yes & $18.2(15.8$ to 20.5$)$ & 11.7 & 30.2 & 3.2 & 2.2 to 4.6 & $<0.001$ \\
\hline \multicolumn{7}{|c|}{ Anxiety $(\mathrm{BAI} \geq 16)$} \\
\hline Yes & $13.0(10.5$ to 15.5$)$ & 7.4 & 23.4 & 3.6 & 2.3 to 5.7 & $<0.001$ \\
\hline \multicolumn{7}{|c|}{ Post-traumatic stress disorder (PCL-C $\geq 35$ ) } \\
\hline No & 83.1 (80.7 to 85.5$)$ & 90.7 & 69.0 & 1.0 & ref & \\
\hline Yes & 16.9 (14.5 to 19.3$)$ & 9.3 & 31.0 & 4.3 & 2.9 to 6.5 & $<0.001$ \\
\hline \multicolumn{7}{|c|}{ Thought of self-harm in past week (EPDS, item 10) } \\
\hline \multicolumn{7}{|c|}{ Psychotropic medication use in the past month } \\
\hline No & 81.1 (78.1 to 84.0 ) & 84.4 & 74.9 & 1.0 & ref & \\
\hline Yes & 18.9 (16.0 to 21.9$)$ & 15.6 & 25.1 & 1.7 & 1.2 to 2.5 & 0.003 \\
\hline
\end{tabular}

${ }^{*}$ Adjusted for maternal age and highest education level.

BAI, Beck Anxiety Inventory; CES-D, Center for Epidemiological Studies Depression Scale; EPDS, Edinburgh Postnatal Depression Scale; IPV, intimate partner violence; PCL-C, Post-Traumatic Stress Disorder Checklist-Civilian version .

2.1 times higher for women with past IPV. Prevalence of post-traumatic stress symptoms and thoughts of self-harm were highest among women with recent IPV $(42.4 \%$ and $21.9 \%$, respectively), compared with $17.2 \%$ and $10.1 \%$ for women with past IPV, and $9.3 \%$ and $4.9 \%$ for women who never reported IPV. More than one in four women (28.1\%) reporting recent exposure to IPV had taken psychotropic medication in the month prior to 10 -year follow-up, compared with $21.6 \%$ with past exposure to IPV, and $15.6 \%$ of women who never reported IPV. Overall, just over half $(54.6 \%)$ of women with recent exposure to IPV reported mental health symptoms, compared with $31.3 \%$ of women with past exposure, and $17 \%$ of women never reporting IPV. Compared with women who never reported IPV, women with recent and past exposure to IPV had a higher likelihood of reporting mental health symptoms at 10 years post partum (Adj OR=5.7, 95\% CI 4.0 to 8.2 and Adj OR=2.1, 95\% CI 1.4 to 3.3, respectively).

\section{DISCUSSION}

Our goal was to examine the relationship between exposure to IPV and maternal physical and mental health 10 years after the birth of a first child. In addition, we sought to differentiate patterns of health for women exposed to recent IPV and those exposed to IPV in the early years after childbirth (but not currently experiencing IPV). Notably, our estimate of the 10-year period prevalence of IPV among this population-based cohort of first-time mothers is higher than the retrospective estimate of lifetime exposure to IPV for women aged 15-44 years reported in the Australian Personal Safety Survey. ${ }^{56}$ It is possible that pregnancy and childrearing confer additional vulnerability to IPV. ${ }^{57}$ Our results make it clear that this vulnerability is not confined to pregnancy and the early years of parenting. Almost one in five women reported recent exposure to IPV (ie, exposure to IPV in the previous 12 months). Of these, just under two-thirds also experienced IPV in the first and/or fourth year post partum, attesting to the longevity of many women's exposure to violence in intimate partner relationships.

Consistent with the findings of other studies, women with recent exposure to IPV reported worse health than women not reporting IPV on almost all measures of physical and mental health. ${ }^{3}$ Significantly, women with past but not recent exposure to IPV-almost $16 \%$ of the cohort-also had higher odds of poor mental and physical health 10 years after the birth of their first child than women not reporting IPV. Adjustment for maternal age and education did not alter findings. While the design of the study does not allow us to establish definitive causal links between exposure to IPV and symptoms of ill health, evidence that past exposure is associated with current health status adds weight to the likelihood that experiencing IPV directly contributes to poor maternal health in both the short and long term. The large effect sizes in our study and consistency of associations across different measures of maternal mental and physical health provide further evidence strengthening the inference that IPV 


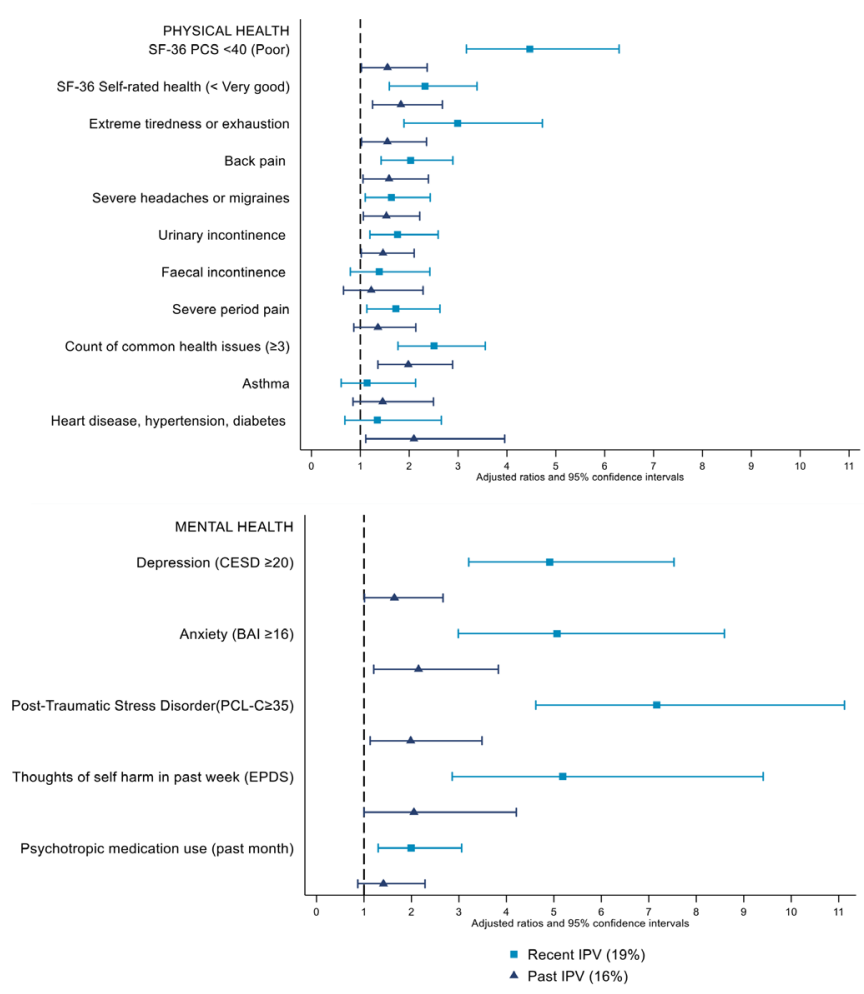

Figure 2 Physical and mental health of women reporting recent IPV and past IPV compared with women not reporting IPV ( $n=1507)$. BAI, Beck Anxiety Inventory; CES-D, Center for Epidemiological Studies Depression Scale; EPDS, Edinburgh Postnatal Depression Scale; IPV, intimate partner violence; PCL-C, Post-Traumatic Stress Disorder Checklist-Civilian version; SF-36 PCS, 36-item Short Form Health Survey Physical Health Component Summary.

contributes to poor health. ${ }^{58}$ Other potential explanatory factors include pathways via clustering of IPV with other risk factors for poor maternal health, such as adverse childhood experiences, poverty and other social health issues. ${ }^{59} 60$

Although the strongest effects were apparent for measures of maternal mental health, marked effects were also apparent for a range of physical health outcomes. Physical symptoms commonly associated with both recent and past IPV in our study include: extreme tiredness, back pain, severe headaches/migraines, urinary incontinence and severe period pain. These health issues are common reasons for presentation to general practitioners and allied health professionals, but may not be widely recognised as potential markers of exposure to IPV. Selfreported health status was also less favourable for women who had recent and past exposure to IPV. This measure has been shown to predict both mortality and morbidity, ${ }^{6162}$ and in our study, was correlated with the evidence of poor physical health on the SF-36 PCS. Importantly, women with past IPV had higher odds of reporting heart disease, hypertension and/or diabetes, confirming findings in a small number of other studies. ${ }^{11}{ }^{1563-66}$ It is plausible that the allostatic load (impact of repeated exposure to chronic stress on physiological and neurological processes) associated with exposure to IPV contributes to higher chronic disease burden. ${ }^{11}$ Lower odds of reporting chronic cardiovascular and metabolic disease among women with recent exposure compared with past exposure has been found in other studies and may reflect a lag in the time between exposure and evidence of impact on cardiovascular and metabolic disease outcomes. ${ }^{15}$

The evidence of a gradient in health, with those not reporting IPV experiencing the best health outcomes, those with recent IPV exposure reporting the poorest outcomes and those with past IPV exposure reporting health outcomes that are intermediate between these two extremes is an important finding. On the one hand, it suggests that for some women, poor health persists well beyond the period when violence appears to have ceased. On the other, it suggests that women no longer exposed to IPV may be able to heal and recover over time. What enables women to achieve positive health outcomes once IPV has ceased is an important area of focus for future research.

Strengths of this study include: recruitment of a community sample of first-time mothers in early pregnancy, the longitudinal design, relatively low attrition of study participants, repeated measurement of IPV using a wellvalidated comprehensive scale, and inclusion of comprehensive measures of maternal physical and mental health. We used standardised measures of depressive, anxiety and post-traumatic stress symptoms, with appropriate cut-off scores for identifying clinically significant symptoms in community samples. Functional health status was assessed with the well-validated SF-36, which includes a summary measure of physical health. Limitations include our inability to calculate a precise response fraction at the time of enrolment and selective attrition of the cohort over time. The fact that the sample is representative for key obstetric characteristics, including method of birth and infant birth weight, is reassuring. Selective attrition of the cohort is likely to have biased prevalence estimates for IPV and some health outcomes in complete case analyses downwards, and is the reason for presenting multiply imputed data. Neither the initial response fraction nor selective attrition at subsequent follow-up is likely to have affected exposure-outcome associations. ${ }^{67}$ The timing of follow-up meant that we were not able to identify women who may have experienced IPV outside the time windows covered by 12-month period prevalence measures at 1,4 and 10 years post partum. It is possible that some women categorised as not reporting IPV may have experienced IPV at other points during the first 10 years post partum. We used a composite variable (combining experiences of physical and emotional IPV) to represent exposure to IPV. This may have resulted in some misclassification of women experiencing other types of IPV not measured in the study (eg, financial abuse), and may also mask differences in the experiences and health outcomes of women exposed to different types of IPV. While analyses assessing associations between IPV and maternal health were adjusted for maternal age and education, not all potential 
Table 4 Physical and mental health of women reporting recent IPV and past IPV compared with women not reporting IPV $(n=1507)$

\begin{tabular}{|c|c|c|c|c|c|c|c|}
\hline & \multicolumn{2}{|c|}{$\begin{array}{l}\text { No IPV reported } \\
(65.2 \%)\end{array}$} & \multicolumn{2}{|c|}{$\begin{array}{l}\text { Past IPV } \\
(15.7 \%)\end{array}$} & \multicolumn{2}{|c|}{$\begin{array}{l}\text { Recent IPV } \\
(19.1 \%)\end{array}$} & \multirow{2}{*}{$\begin{array}{l}\text { Test for } \\
\text { trend }\end{array}$} \\
\hline & $\%$ & Adj OR* $(95 \% \mathrm{Cl})$ & $\%$ & Adj OR* $(95 \% \mathrm{Cl})$ & $\%$ & Adj OR* $(95 \% \mathrm{Cl})$ & \\
\hline $\begin{array}{l}\text { SF-36 Physical Component Score } \\
<40 \text { (poor) }\end{array}$ & 21.1 & 1.0 (ref) & 30.1 & $1.6(1.0$ to 2.4$)$ & 55.0 & 4.5 (3.2 to 6.3$)$ & $<0.001$ \\
\hline $\begin{array}{l}\text { SF-36 self-rated health less than } \\
\text { 'very good' }\end{array}$ & 33.2 & 1.0 (ref) & 48.3 & 1.8 (1.3 to 2.7$)$ & 54.3 & 2.3 (1.6 to 3.4$)$ & $<0.001$ \\
\hline \multicolumn{8}{|l|}{ Common health issues } \\
\hline Extreme tiredness or exhaustion & 58.7 & 1.0 (ref) & 68.6 & 1.6 (1.0 to 2.4$)$ & 80.6 & $3.0(1.9$ to 4.7$)$ & $<0.001$ \\
\hline Back pain & 51.8 & 1.0 (ref) & 63.2 & $1.6(1.1$ to 2.4$)$ & 68.6 & 2.0 (1.4 to 2.9$)$ & $<0.001$ \\
\hline Severe headaches or migraines & 29.5 & 1.0 (ref) & 39.6 & 1.5 (1.1 to 2.2$)$ & 41.2 & $1.6(1.1$ to 2.4$)$ & 0.006 \\
\hline Urinary incontinence & 30.7 & 1.0 (ref) & 38.3 & $1.5(1.0$ to 2.1$)$ & 42.2 & $1.8(1.2$ to 2.6$)$ & 0.002 \\
\hline \multicolumn{8}{|l|}{ Medical conditions } \\
\hline Asthma & 11.7 & 1.0 (ref) & 17.0 & 1.5 (0.9 to 2.5$)$ & 14.0 & $1.1(0.6$ to 2.1$)$ & 0.490 \\
\hline $\begin{array}{l}\text { Heart disease, hypertension and/ } \\
\text { or diabetes }\end{array}$ & 6.7 & 1.0 (ref) & 13.7 & 2.1 (1.1 to 4.0$)$ & 9.3 & $1.3(0.7$ to 2.7$)$ & 0.172 \\
\hline \multicolumn{8}{|l|}{ Mental health } \\
\hline Depression (CES-D $\geq 20$ ) & 11.7 & 1.0 (ref) & 18.4 & 1.6 (1.0 to 2.7$)$ & 39.9 & 4.9 (3.2 to 7.5$)$ & $<0.001$ \\
\hline Anxiety (BAI $\geq 16)$ & 7.4 & 1.0 (ref) & 15.4 & 2.1 (1.2 to 3.8$)$ & 29.9 & 5.1 (3.0 to 8.6$)$ & $<0.001$ \\
\hline $\begin{array}{l}\text { Post-traumatic stress disorder } \\
\text { (PCL-C } \geq 35)\end{array}$ & 9.3 & 1.0 (ref) & 17.2 & 2.0 (1.1 to 3.5$)$ & 42.4 & $7.2(4.6$ to 11.1$)$ & $<0.001$ \\
\hline
\end{tabular}

${ }^{*}$ Adjusted for maternal age and highest education level.

BAI, Beck Anxiety Inventory; CES-D, Center for Epidemiological Studies Depression Scale; EPDS, Edinburgh Postnatal Depression Scale; IPV, intimate partner violence; PCL-C, Post-Traumatic Stress Disorder Checklist-Civilian version; SF-36, 36-item Short Form Health Survey.

confounders have been accounted for and causal relationships between exposure to IPV and outcomes examined cannot be established. Further analyses of study data will consider these issues in greater depth. In particular, we intend to (1) explore different ways of looking at the timeframe over which violence occurred (eg, women with recent but not past exposure vs women with persisting exposure), (2) assess the health of women exposed to different types of IPV, and (3) examine intergenerational patterns of exposure to IPV and the broader context in which IPV is occurring.

The most important finding of this study is the extent to which both recent and past exposure to IPV are associated with poor maternal physical and mental health. Evidence that women with past exposure to IPV remain at higher risk for a wide range of mental and physical health problems illustrates the high personal costs and longer term consequences of IPV for women's health. ${ }^{20}$ Drawing on Australian population-based data, Ayre et al found that lifetime exposure to IPV posed a greater risk for ill health among women aged 15-44 years of age than seven other major risk factors for morbidity and mortality. ${ }^{20}$ Despite growing recognition of the significant burden of morbidity (and mortality) associated with IPV, the health sector has been relatively slow to respond. ${ }^{68} 69$ Australian policy efforts have tended to focus on police, legal systems, advocacy and housing sectors, with limited focus or resources directed towards strengthening health sector responses outside the maternity and early childhood sectors. ${ }^{70} 71$ Our results suggest that the focus on maternity and early childhood services is warranted, but needs to be matched by equivalent efforts to identify and support women across the lifespan, including women whose exposure to IPV may be in the past. For general 
practitioners, maternal and child health services and allied health professionals providing care to women in the early years of parenting, the findings are a reminder that presenting problems such as tiredness, back pain or incontinence, and patterns of physical and mental morbidity (eg, comorbid physical and mental health symptoms) may be occurring in the context of IPV. Once IPV is identified as a potential contributing or contextualising factor, the nature of health sector response needs to be tailored to take this into account. ${ }^{68}$ For women whose exposure to IPV had ceased, clinical responses are likely to look different to the response required for women whose exposure to IPV is current. ${ }^{72}$

\section{CONCLUSIONS}

Both recent and past exposure to IPV are associated with poor maternal physical and mental health 10 years after a first birth. Health services and advocacy organisations providing support to women need to be alert to the consistent relationship between IPV and a range of physical and mental health conditions, which may persist even after IPV has ceased.

Acknowledgements We are extremely grateful to all of the women taking part in the study; to members of the Maternal Health Study Collaborative Group (including Harriet Hiscock, Helen Herrman, Jan Nicholson, Sheena Reilly, George Patton, Emma Scibberas and Liz Westrupp) who contributed to design of study instruments and data collection procedures for 10-year follow-up; and to members of the Maternal Health Study research team who have contributed to data collection (Leisje Brice, Maggie Flood, Ann Krastev, Ellie McDonald, Sue Perlen and Monique Seymour).

Contributors SJB conceived the study and developed the study protocol in collaboration with DG, HW, RG and KH. DG and SJB conducted analyses. SJB wrote the manuscript. DG and HW were involved in data collection and curation. All authors (SJB, LJC, KF, KH, FKM, SP, HW, RG, DG) contributed to interpretation of data, reviewed earlier versions of the manuscript and approved the final version.

Funding This work was supported by: project grants \#199222, \#433006 and \#4912015 from the Australian National Health and Medical Research Council (NHMRC), an NHMRC Research Fellowship awarded to SJB, postdoctoral fellowships awarded to DG and LC by the NHMRC funded Safer Families Centre of Research Excellence (\#1116690), and by the Victorian Government's Operational Infrastructure Program (grant number not available).

Competing interests None declared.

Patient consent for publication Not required.

Ethics approval Ethics approval was obtained from ethics committees in participating hospitals, the La Trobe University Human Research Ethics Committee and Royal Children's Hospital Human Research Ethics Committee.

Provenance and peer review Not commissioned; externally peer reviewed.

Data availability statement Data are available upon reasonable request. Further information about the Maternal Health Study can be obtained from the LifeCourse website. The Maternal Health Study data are not open access. Requests for collaboration can be sent to Professor Brown (stephanie.brown@mcri.edu.au) and will be considered by the Maternal Health Study investigative team.

Supplemental material This content has been supplied by the author(s). It has not been vetted by BMJ Publishing Group Limited (BMJ) and may not have been peer-reviewed. Any opinions or recommendations discussed are solely those of the author(s) and are not endorsed by BMJ. BMJ disclaims all liability and responsibility arising from any reliance placed on the content. Where the content includes any translated material, BMJ does not warrant the accuracy and reliability of the translations (including but not limited to local regulations, clinical guidelines, terminology, drug names and drug dosages), and is not responsible for any error and/or omissions arising from translation and adaptation or otherwise.
Open access This is an open access article distributed in accordance with the Creative Commons Attribution Non Commercial (CC BY-NC 4.0) license, which permits others to distribute, remix, adapt, build upon this work non-commercially, and license their derivative works on different terms, provided the original work is properly cited, appropriate credit is given, any changes made indicated, and the use is non-commercial. See: http://creativecommons.org/licenses/by-nc/4.0/.

ORCID iDs

Stephanie J Brown http://orcid.org/0000-0001-9812-0067

Deirdre Gartland http://orcid.org/0000-0001-6749-8147

\section{REFERENCES}

1 World Health Organisation. Global and regional estimates of violence against women: prevalence and health effects of intimate partner violence and non-partner sexual violence. Geneva: World Health Organisation, 2013.

2 World Health Organisation. Preventing intimate partner and sexual violence against women: taking action and generating evidence. Geneva: World Health Organisation, 2010.

3 Bacchus LJ, Ranganathan M, Watts C, et al. Recent intimate partner violence against women and health: a systematic review and metaanalysis of cohort studies. BMJ Open 2018;8:e019995.

4 Devries KM, Mak JY, Bacchus LJ, et al. Intimate partner violence and incident depressive symptoms and suicide attempts: a systematic review of longitudinal studies. PLoS Med 2013;10:e1001439.

5 Lagdon S, Armour C, Stringer M. Adult experience of mental health outcomes as a result of intimate partner violence victimisation: a systematic review. Eur J Psychotraumatol 2014;5:24794.

6 Dillon G, Hussain R, Loxton D, et al. Mental and physical health and intimate partner violence against women: a review of the literature. Int J Family Med 2013;2013:1-15.

7 Beydoun HA, Beydoun MA, Kaufman JS, et al. Intimate partner violence against adult women and its association with major depressive disorder, depressive symptoms and postpartum depression: a systematic review and meta-analysis. Soc Sci Med 2012;75:959-75.

8 Golding JM. Intimate partner violence as a risk factor for mental disorders: a meta-analysis. J Fam Violence 1999;14:99-132.

9 Sugg N. Intimate partner violence: prevalence, health consequences, and intervention. Med Clin North Am 2015;99:629-49.

10 Fanslow J, Robinson E. Violence against women in New Zealand: prevalence and health consequences. N Z Med J 2004;117:U1173.

11 Clark CJ, Alonso A, Everson-Rose SA, et al. Intimate partner violence in late adolescence and young adulthood and subsequent cardiovascular risk in adulthood. Prev Med 2016;87:132-7.

12 Bonomi AEet al. Medical and psychosocial diagnoses in women with a history of intimate partner violence. Arch Intern Med 2009;169:1692-7.

13 Campbell J, Jones AS, Dienemann J, et al. Intimate partner violence and physical health consequences. Arch Intern Med 2002;162:1157-63.

14 Loxton D, Schofield M, Hussain R, et al. History of domestic violence and physical health in midlife. Violence Against Women 2006;12:715-31.

15 Ruiz-Pérez I, Plazaola-Castaño J, Del Río-Lozano M. Physical health consequences of intimate partner violence in Spanish women. Eur J Public Health 2007;17:437-43.

16 Carbone-López K, Kruttschnitt C, Macmillan R. Patterns of intimate partner violence and their associations with physical health, psychological distress, and substance use. Public Health Rep 2006;121:382-92.

17 Wuest J, Merritt-Gray M, Lent B, et al. Patterns of medication use among women survivors of intimate partner violence. Can J Public Health 2007;98:460-4.

18 Alsaker K, Moen BE, Nortvedt MW, et al. Low health-related quality of life among abused women. Qual Life Res 2006;15:959-65.

19 Bonomi AE, Thompson RS, Anderson M, et al. Intimate partner violence and women's physical, mental, and social functioning. Am J Prev Med 2006;30:458-66.

20 Ayre J, Lum On M, Webster K, et al. Examination of the burden of disease of intimate partner violence against women in 2011: final report. Sydney: ANROWS: ANROWS Horizons, 2016.

21 Ellsberg M, Jansen HAFM, Heise L, et al. Intimate partner violence and women's physical and mental health in the WHO multi-country study on women's health and domestic violence: an observational study. The Lancet 2008;371:1165-72.

22 Tsai AC. Intimate partner violence and population mental health: why poverty and gender inequities matter. PLoS Med 2013;10:e1001440. 
23 Yakubovich AR, Heron J, Feder G, et al. Long-Term exposure to neighborhood deprivation and intimate partner violence among women. Epidemiology 2020;31:272-81.

24 Wathen CN, Tanaka M, MacGregor JCD, et al. Trajectories for women who disclose intimate partner violence in health care settings: the key role of abuse severity. Int J Public Health 2016;61:873-82.

25 Ahmadabadi Z, Najman JM, Williams GM, et al. Intimate partner violence in emerging adulthood and subsequent substance use disorders: findings from a longitudinal study. Addiction 2019;114:1264-73.

26 Suglia SF, Duarte CS, Sandel MT. Housing quality, housing instability, and maternal mental health. J Urban Health 2011;88:1105-16.

27 Brown SJ, Mensah F, Giallo R, et al. Intimate partner violence and maternal mental health ten years after a first birth: an Australian prospective cohort study of first-time mothers. J Affect Disord 2020;262:247-57.

28 Taft AJ, Powell RL, Watson LF, et al. Factors associated with induced abortion over time: secondary data analysis of five waves of the Australian Longitudinal Study on Women's Health. Aust N Z J Public Health 2019;43:137-42.

29 Flach C, Leese M, Heron J, et al. Antenatal domestic violence, maternal mental health and subsequent child behaviour: a cohort study. BJOG 2011;118:1383-91.

30 Boden JM, Fergusson DM, Horwood LJ. Alcohol misuse and violent behavior: findings from a 30-year longitudinal study. Drug Alcohol Depend 2012;122:135-41.

31 Zlotnick C, Johnson DM, Kohn R. Intimate partner violence and long-term psychosocial functioning in a national sample of American women. J Interpers Violence 2006;21:262-75.

32 Brown SJ, Lumley JM, McDonald EA, et al. Maternal health study: a prospective cohort study of nulliparous women recruited in early pregnancy. BMC Pregnancy Childbirth 2006;6:12.

33 Hegarty K, Bush R, Sheehan M. The composite abuse scale: further development and assessment of reliability and validity of a multidimensional partner abuse measure in clinical settings. Violence Vict 2005;20:529-47.

34 Hegarty K, Sheehan M, Schonfeld C. Schonfeld C. a multidimensional definition of partner abuse: development and preliminary validation of the composite abuse scale. J Fam Violence 1999;14:399-415.

35 Hegarty K. Definitional issues: What is intimate partner abuse and how common is it? In: Roberts GHK, Feder G, eds. Intimate partner abuse and health professionals. London, Uk: Elsevier, 2006.

36 Hegarty KL, O'Doherty LJ, Chondros P, et al. Effect of type and severity of intimate partner violence on women's health and service use: findings from a primary care trial of women afraid of their partners. J Interpers Violence 2013;28:273-94.

37 Brazier JE, Harper R, Jones NM, et al. Validating the SF-36 health survey questionnaire: new outcome measure for primary care. BMJ 1992;305:160-4.

38 Ware JE, Aaronson NK, Brazier J, et al. The factor structure of the SF-36 health survey in 10 countries: results from the IQOLA project. International quality of life assessment. J Clin Epidemiol 1998;51:1159-65.

39 Australian Bureau of Statistics. National health survey: SF-36 population norms. Canberra, Australia, 1995

40 Ware JE. Sf-36 health survey update. Spine 2000;25:3130-9.

41 Sandvik $H$, Seim A, Vanvik A, et al. A severity index for epidemiological surveys of female urinary incontinence: comparison with 48-hour pad-weighing tests. Neurourol Urodyn 2000;19:137-45.

42 Talley NJ, Newman P, Boyce PM, Owen BK, et al. Initial validation of a bowel symptom questionnaire* and measurement of chronic gastrointestinal symptoms in Australians. Aust N Z J Med 1995;25:302-8.

43 Abrams P, Cardozo L, Fall M, et al. The standardisation of terminology of lower urinary tract function: report from the standardisation Sub-committee of the International continence Society. Am J Obstet Gynecol 2002;187:116-26.

44 Radloff LS. The CES-D scale. Appl Psychol Meas 1977;1:385-401.

45 Vilagut G, Forero CG, Barbaglia G, et al. Screening for depression in the general population with the center for epidemiologic studies depression (CES-D): a systematic review with meta-analysis. PLoS One 2016;11:e0155431-17.

46 Beck AT, Epstein N, Brown G, et al. An inventory for measuring clinical anxiety: psychometric properties. J Consult Clin Psychol 1988;56:893-7.
47 Bardhoshi G, Duncan K, Erford BT. Psychometric meta-analysis of the English version of the Beck anxiety inventory. J Couns Dev 2016;94:356-73.

48 Conybeare D, Behar E, Solomon A, et al. The PTSD ChecklistCivilian version: reliability, validity, and factor structure in a nonclinical sample. J Clin Psychol 2012;68:699-713.

49 Wilkins KC, Lang AJ, Norman SB. Synthesis of the psychometric properties of the PTSD checklist (PCL) military, civilian, and specific versions. Depress Anxiety 2011;28:596-606.

50 Freedy JR, Steenkamp MM, Magruder KM, et al. Post-Traumatic stress disorder screening test performance in civilian primary care. Fam Pract 2010;27:615-24.

51 Walker EA, Newman E, Dobie DJ, et al. Validation of the PTSD checklist in an HMO sample of women. Gen Hosp Psychiatry 2002;24:375-80.

52 Cox JL, Holden JM, Sagovsky R. Detection of postnatal depression. development of the 10-item Edinburgh postnatal depression scale. Br J Psychiatry 1987;150:782-6.

53 Cox Jet al. Validation of the Edinburgh postnatal depression scale (EPDS) in non-postnatal women. J Affect Disord 1996;39:185-9.

54 StataCorp. Stata statistical software. release 16. College TX: StataCorp LP, 2019.

55 Brown SJ, McDonald EA, Krastev AH. Fear of an Intimate Partner and Women's Health in Early Pregnancy: Findings from the Maternal Health Study. Birth 2008;35:293-302.

56 Australian Bureau of Statistics. Personal safety, Australia (cat No. 4906.0). Canberra, Australia: Author, 2016.

57 Tsai AC, Tomlinson M, Comulada WS, et al. Intimate partner violence and depression symptom severity among South African women during pregnancy and postpartum: population-based prospective cohort study. PLoS Med 2016;13:e1001943.

58 Hill AB. The environment and disease: association or causation? Proc $R$ Soc Med 1965;58:295-300.

59 Gartland D, Giallo R, Woolhouse H, et al. Intergenerational Impacts of Family Violence - Mothers and Children in a Large Prospective Pregnancy Cohort Study. EClinicalMedicine 2019;15:51-61.

60 Mendenhall E, Kohrt BA, Norris SA, et al. Non-Communicable disease syndemics: poverty, depression, and diabetes among lowincome populations. Lancet 2017;389:951-63.

61 Sorlie PD, Backlund E, Keller JB. Us mortality by economic, demographic, and social characteristics: the National longitudinal mortality study. Am J Public Health 1995:85:949-56.

62 Fryers T, Melzer D, Jenkins R. Social inequalities and the common mental disorders: a systematic review of the evidence. Soc Psychiatry Psychiatr Epidemiol 2003;38:229-37.

63 Hegarty K, Gunn J, Chondros P, et al. Association between depression and abuse by partners of women attending general practice: descriptive, cross sectional survey. BMJ 2004;328:621-4.

64 Wright EN, Hanlon A, Lozano A, et al. The association between intimate partner violence and 30-year cardiovascular disease risk among young adult women. $J$ Interpers Violence 2018:088626051881632

65 Mason SM, Wright RJ, Hibert EN, et al. Intimate partner violence and incidence of type 2 diabetes in women. Diabetes Care 2013;36:1159-65.

66 Mason SM, Wright RJ, Hibert EN, et al. Intimate partner violence and incidence of hypertension in women. Ann Epidemiol 2012;22:562-7.

67 Mealing NM, Banks E, Jorm LR, et al. Investigation of relative risk estimates from studies of the same population with contrasting response rates and designs. BMC Med Res Methodol 2010;10:26.

68 García-Moreno C, Hegarty K, d'Oliveira AFL, et al. The health-systems response to violence against women. Lancet 2015;385:1567-79.

69 García-Moreno C. Dilemmas and opportunities for an appropriate health-service response to violence against women. Lancet 2002;359:1509-14.

70 State of Victoria. Royal Commission into family violence: summary and recommendations: 2014-6.

71 Council of Australian Governments. National plan to reduce violence against women and their children 2010-2022 (the National plan), 2011

72 Reisenhofer SA, Hegarty K, Valpied J, et al. Longitudinal changes in self-efficacy, mental health, abuse, and stages of change, for women fearful of a partner: findings from a primary care trial (weave). $J$ Interpers Violence 2019;34:337-65. 